\title{
Combination Therapy of Nifedipine and Sulphonylureas Exhibits a Mutual Antagonistic Effect on the Endothelial Cell Dysfunction Induced by Hyperglycemia Linked to Vascular Disease
}

\author{
Li-Ping Wang ${ }^{a}$ Yu Jiang ${ }^{a}$ Hong Yang ${ }^{a}$ Cheng Peng ${ }^{a}$ Chuan Zhang ${ }^{d}$ Xia Tao ${ }^{a}$ \\ He-Hui Xie ${ }^{a, b, c}$
}

aDepartment of Pharmacy, Shanghai Changzheng Hospital, The Second Military Medical University, Shanghai, 'bThird Xiangya Hospital and the Institute of Vascular Disease and Translational Medicine, Central South University, Changsha, 'Hongqiao International Institute of Medicine, Shanghai Tongren Hospital and Faculty of Public Health, Shanghai Jiao Tong University School of Medicine, Shanghai, dDepartment of Identification of Traditional Chinese Medicine, The Second Military Medical University, Shanghai, China

\section{Key Words}

Nifedipine $\cdot$ Sulphonylurea $\cdot \mathrm{HUVECS} \cdot$ Antagonism $\bullet \mathrm{NO} / \mathrm{O}_{2}^{-}$level

\begin{abstract}
Background/Aims: By inducing severe endothelial impairment, hypertension and diabetes are two leading causes of morbidity and mortality. Hypertensive patients with concomitant diabetes must take both antihypertensive and hypoglycaemic medications, for which there is a lack of experimental and clinical guidelines. This study aimed to examine the interaction between these two types of medication on the endothelial cell function. Methods: The effect of antihypertensive (nifedipine and irbesartan) and anti-diabetic (metformin and glibenclamide/glimepiride) drugs on human umbilical vein cells (HUVECs) function was examined using a modified Boyden chamber assay. The intracellular $\mathrm{NO}$ and $\mathrm{O}_{2}{ }^{-}$levels of HUVECs were detected through flow cytometry. Results: Our findings showed that nifedipine/ sulphonylurea monotherapy significantly attenuated high glucose-induced (33 mM) HUVECs migration incapacity, while combination therapy of nifedipine and glibenclamide/glimepiride showed no protective effect. Both nifedipine/metformin monotherapy and combined therapy significantly mitigated the migration incapacity induced by high glucose in HUVECs. Combined with either metformin or sulphonylureas, irbesartan therapy was able to attenuate the high glucose-induced migration incapacity of HUVECs. Nifedipine monotherapy decreased the $\mathrm{O}_{2}-$ levels and increased the NO levels in in vitro-cultured HUVECs treated with high glucose. However, the combination therapy of nifedipine and glibenclamide increased the $\mathrm{O}_{2}^{-}$levels

L.-P. Wang, Y. Jiang and H. Yang contributed equally to this work.

Dr. He-Hui Xie and Dr. Xia Tao

Hongqiao International Institute of Medicine, Shanghai Tongren Hospital and Faculty of Public Health, Shanghai Jiao Tong University School of Medicine, Shanghai 200025, (China); Shanghai Changzheng Hospital, Second Military Medical School, Shanghai 200003, (China); E-Mail xhhtom@263.net / taoxia2003@126.com
\end{abstract}

KARGER 
and decreased the NO levels compared to the nifedipine monotherapeutic group. Conclusion: The nifedipine and glibenclamide/glimepiride combination exerted a mutual antagonistic effect on the protection from high glucose-induced impairment in endothelial cells, which might be partially attributed to the increased $\mathrm{O}_{2}^{-}$level and decreased $\mathrm{NO}$ level. These results imply that calcium channel blockers + sulphonylurea combination therapy warrants further attention in patients suffering from both hypertension and diabetes.

(C) 2016 The Author(s)

Published by S. Karger AG, Basel

\section{Introduction}

Hypertension and diabetes are two major health problems that affect a majority of the general population. The overall prevalence of hypertension appears to be approximately $30-45 \%$ worldwide, with a steep increase associated with ageing, according to the 2013 hypertension guidelines from the ESH (European Society of Hypertension) and the ESC (European Society of Cardiology) [1]. While the global incidence of diabetes was estimated at $6.4 \%$ in 2010 , it is expected to rise to $7.7 \%$ by 2030 [2]. In diabetics, the rate of hypertension is approximately double compared to that in patients without diabetes. Conversely, it has been suggested that hypertensive patients are more predisposed to the development of diabetes compared to normotensive patients [3]. It is estimated that one would expect $29.3 \%$ of diabetic patients to have hypertension and $7.8 \%$ of hypertensive patients to have diabetes [4].

Moreover, hypertensive patients with comorbid diabetes are declined to develop more severe microvascular complications $[5,6]$. Vascular disease is a major cause of death and disability in hypertensive or diabetic patients [7]. Abnormalities in endothelial cell morphology and function are recognized as features of diabetes [8,9], while endothelial dysfunction is also characteristic of hypertension [10]. Therefore, endothelial function reservation has been more than vital in cardiovascular disease treatment $[11,12]$.

Patients on the hypertension-diabetes continuum must take anti-diabetic drugs, as well as antihypertensive drugs. However, there are few guidelines governing the co-administration of these two types of medications. In this work, nifedipine/irbesartan and metformin/ glibenclamide/glimepiride were investigated as representatives of antihypertensive and hypoglycaemic drugs, all of which are frequently used singly or in combination in clinics. We focused on the effect of antihypertensive and hypoglycaemic co-treatment on the high glucose-induced migration incapacity of human umbilical vein endothelial cells (HUVECs), and we investigated the underlying mechanism in terms of oxidative stress.

\section{Materials and Methods}

\section{HUVECS culture and treatment}

HUVECs were purchased from the Chinese Academy of Sciences (Shanghai, China). Cells were cultured in RAPI 1640 medium (Gibco, America) supplemented with 10\% foetal bovine serum (FBS) and penicillinstreptomycin $0.5 \%$ at $37^{\circ} \mathrm{C}$ in a $\mathrm{CO}_{2}$ incubator according to the manufacturer's instructions. HUVECs were seeded in 6-well plates at a density of $1 \times 10^{5}$ cells $/ \mathrm{mL}$ to reach $80-90 \%$ confluence. The cell number was manually counted in a hemocytometer. Cells were fasted overnight in serum-free 1640 medium followed by incubation for 24 hours with high glucose (33 mM) in the absence or presence of nifedipine (Sigma, N7634; $1 \mu \mathrm{m}$ ), irbesartan (Sigma, 1347700; 5 $\mu \mathrm{m}$ ), metformin (Sigma, D150959; 10 $\mu \mathrm{M}$ ), glibenclamide (Sigma, G0639; $0.2 \mu \mathrm{M}$ ) and glimepiride (Sigma, G2295; $1 \mu \mathrm{M}$ ). The glucose level (33 mM) used in the present work was determined according to previous studies $[8,11,13]$. The concentrations of the antidiabetic and antihypertensive agents were determined according to their plasma concentrations [14-17].

In-vitro cells migration assay

In brief, HUVECs $\left(5 \times 10^{4}\right.$ cells $\left./ 100 \mu \mathrm{L}\right)$ were seeded into the upper Boyden's chamber with RAPI 1640 medium and placed in a 24-well plate (Corning, Transwell ${ }^{\circledR}, 3527$ ). The lower chambers were loaded 


\section{Cellular Physiology Cell Physiol Biochem 2016;38:2337-2347

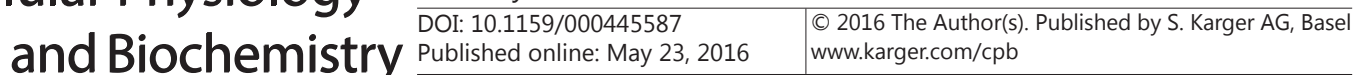 \\ Wang et al.: Nifedipine, Sulphonylureas and Endothelial Cell Dysfunction}

with RAPI 1640 supplemented with $50 \mathrm{ng} / \mathrm{ml}$ vascular endothelial growth factor (VEGF). Endothelial cells were allowed to migrate for 24 hours and then fixed and stained with Hoechst $33258\left(5 \times 10^{-6} \mathrm{~mol} / \mathrm{L}, 10\right.$ min, Molecular Probes). The number of migrated cells on the lower side of the membrane was counted at a magnification of $\times 100$, and the mean value of five random fields was determined per sample in triplicate [18].

Intracellular nitric oxide \& superoxide measurement

The intracellular $\mathrm{NO}$ and $\mathrm{O}_{2}^{-}$levels were respectively determined using dihydroethidium (DHE; Invitrogen, D11347) and 4-amino- 5-methylamine- 2', 7'-difluorofluorescein (DAF-FM) diacetate (Invitrogen, D23844) [19]. After 24 hours of treatment, HUVECs were trypsinized and rinsed twice with RAPI 1640 medium and then incubated with DHE $\left(10^{-6} \mathrm{~mol} / \mathrm{L}\right)$ or DAF-FM $\left(10^{-6} \mathrm{~mol} / \mathrm{L}\right)$ for 15 minutes at $37^{\circ} \mathrm{C}$ in the dark. After incubation, the cells were washed twice with PBS and re-suspended in $300 \mu \mathrm{l}$ of $2 \%$ paraformaldehyde. The DHE fluorescence intensity in the cells was determined through flow cytometry.

\section{Statistical Analysis}

The results are expressed as the mean \pm SEM. Comparison among different groups was performed using One-way ANOVA [20], followed by a Newman-Keuls multiple comparison test, and $P<0.05$ was considered statistically significant.

\section{Results}

Nifedipine + metformin combination therapy mitigated the migration incapacity of HUVECs in high glucose, while nifedipine + glibenclamide exhibited an antagonistic effect on endothelial cell function

HUVECs exposed to high glucose $(33 \mu \mathrm{M})$ for 24 hours demonstrated a significantly impaired migration function compared to the control group (0.561 \pm 0.007 vs $1.00 \pm 0.022$, $P<0.01$; Fig. 1). Nifedipine monotherapy (1 $\mu \mathrm{m}, 24$ hours) significantly mitigated the

Fig. 1. Nifedipine and glibenclamide combined therapy abolished the protective effect of monotherapies from high glucose-induced migration incapacity (33 mM). (A) Representative images of migration assay. (B) The results from the migration assay of HUVECs. Values were normalized to the controls. ${ }^{* *} P<0.01, \mathrm{n}$ $=15$. Scale bar: $100 \mu \mathrm{m}$. Con, HUVECs incubated in RAPI 1640 medium; Glu, HUVECs incubated in $33 \mathrm{mM}$ glucose (high glucose) for 24 hours; Glu + Nif, high glucose-treated HUVECs incubated in $1 \mu \mathrm{M}$ nifedipine for 24 hours; Glu + Gly, high glucose-treated HUVECs incubated in $0.2 \mu \mathrm{M}$ glibenclamide for 24 hours; Glu + Met, high glucose-treated HUVECs incubated in $10 \mu \mathrm{M}$ metformin for 24 hours; Glu + Nif + Gly, high glucose-treated HUVECs incubated in $1 \mu \mathrm{M}$ nifedipine and $0.2 \mu \mathrm{M}$ glibenclamide for 24 hours; Glu + Nif + Met, high glucose-treated HUVECs incubated in $1 \mu \mathrm{M}$ nifedipine and $10 \mu \mathrm{M}$ metformin for 24 hours.

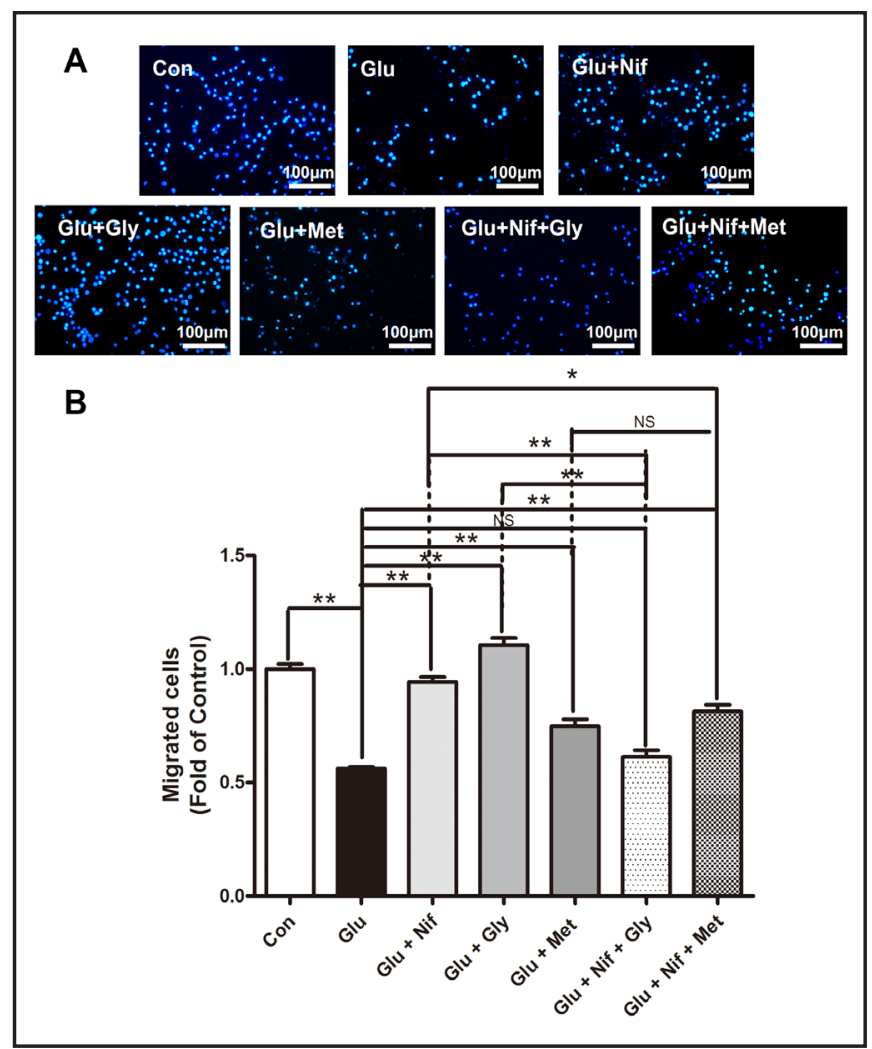


Fig. 2. Irbesartan therapy combined with glibenclamide or metformin mitigated migration incapacity in HUVECs induced by $33 \mathrm{mM}$ glucose treatment. (A) Representative images of the migration assay. (B) The results of the migration assay of HUVECs. The values are normalized to the controls. $* * P<0.01, \mathrm{n}=15$. Scale bar: $100 \mu \mathrm{m}$. Con, cells incubated in RAPI 1640 medium; Glu, cells incubated in $33 \mathrm{mM}$ glucose (high glucose) for 24 hours; Glu + Irb, high glucose-treated HUVECs incubated in $5 \mu \mathrm{M}$ irbesartan for 24 hours; Glu + Gly, high glucose-treated HUVECs incubated with $0.2 \mu \mathrm{M}$ glibenclamide for 24 hours; Glu + Met, high glucose-treated HUVECs incubated in 10 $\mu \mathrm{M}$ metformin for 24 hours; Glu + Irb + Gly, high glucosetreated HUVECs incubated in $5 \mu \mathrm{M}$ irbesartan and 0.2

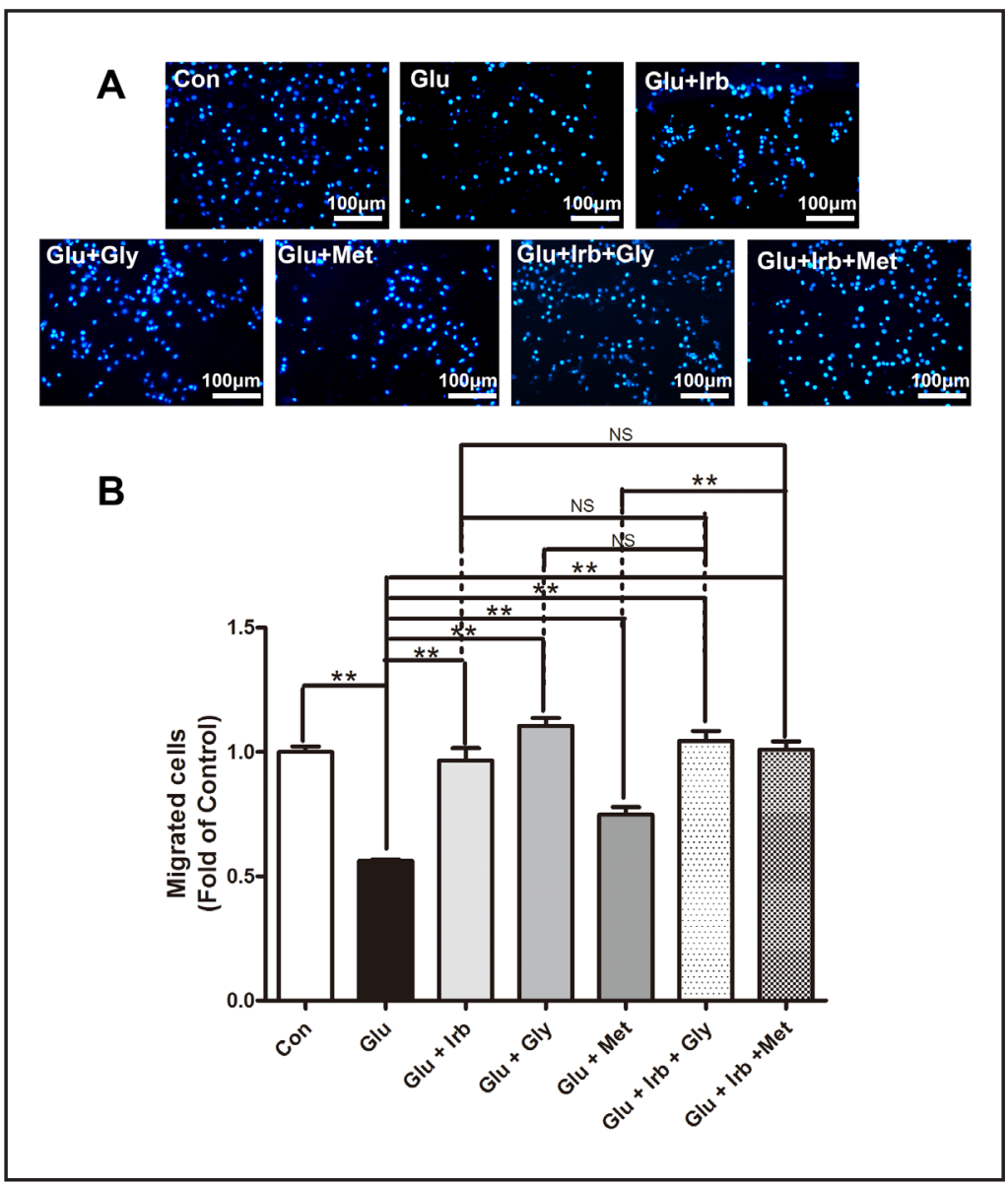
$\mu \mathrm{M}$ glibenclamide for 24 hours; Glu + Irb + Met, high glucose-treated HUVECs incubated in $5 \mu \mathrm{M}$ irbesartan and $10 \mu \mathrm{M}$ metformin for 24 hours.

HUVECs incapacity induced by high glucose $(0.943 \pm 0.022$ vs $0.561 \pm 0.007, P<0.01$; Fig. 1$)$. However, it was found that the combination therapy of nifedipine and glibenclamide $(0.2 \mu \mathrm{M}$, 24 hours) did not improve the migration function of high glucose-treated HUVECs $(0.613$ \pm 0.029 vs $0.561 \pm 0.007, P>0.05$; Fig. 1 ). On the contrary, nifedipine therapy combined with metformin $(10 \mu \mathrm{M}, 24$ hours) significantly reversed the migration incapacity of HUVECs induced by high glucose $(0.814 \pm 0.029$ vs $0.561 \pm 0.007, P<0.01$; Fig. 1$)$. In addition, endothelial cell dysfunction was significantly improved by glibenclamide/metformin monotherapy (Glibenclamide monotherapy: $1.11 \pm 0.031, P<0.01$ vs the high glucose group; metformin monotherapy: $0.748 \pm 0.030, P<0.01$ vs the high glucose group; Fig. 1 ).

Irbesartan combined with glibenclamide or metformin reversed the HUVECs dysfunction induced by high glucose

It was found that irbesartan monotherapy significantly mitigated the incapacity of HUVECs induced by high glucose $(0.966 \pm 0.050$ vs $0.561 \pm 0.007, P<0.01$; Fig. 2), as did the combination therapies of irbesartan + glibenclamide or metformin (Irbesartan + glibenclamide combined therapy: $1.04 \pm 0.041$; Irbesartan + metformin: $1.01 \pm 0.034$; Fig. 2).

Nifedipine combined with glibenclamide treatment decreased intracellular NO levels and increased $\mathrm{O}_{2}^{-}$levels in HUVECS

Flow cytometry analysis of the $\mathrm{NO}$ and $\mathrm{O}_{2}^{-}$levels showed that nifedipine monotherapy increased the $\mathrm{NO}$ level and significantly decreased $\mathrm{O}_{2}^{-}$level in HUVECs compared to the high glucose group (NO level: $1.23 \pm 0.037$ vs $1.00 \pm 0.083, P>0.05 ; \mathrm{O}_{2}^{-}$level: $0.772 \pm 0.047$ vs 
A

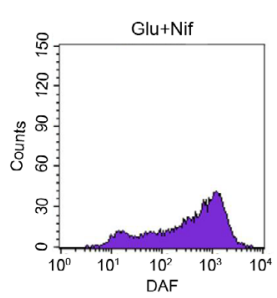

B

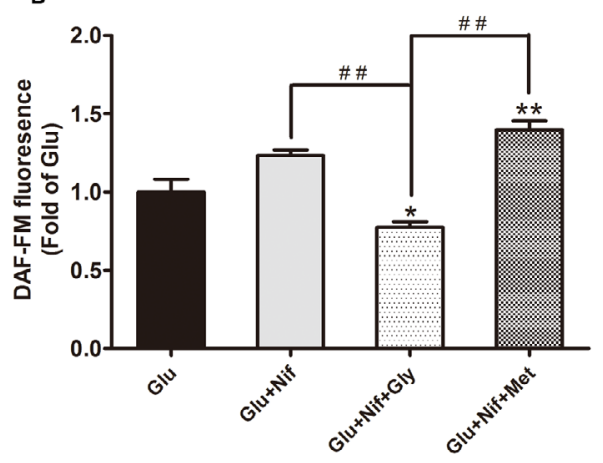

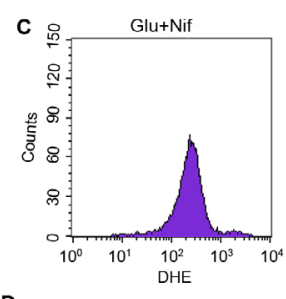

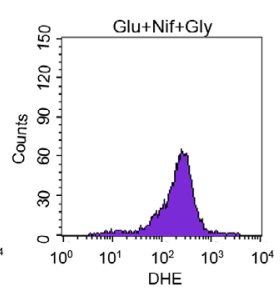

D

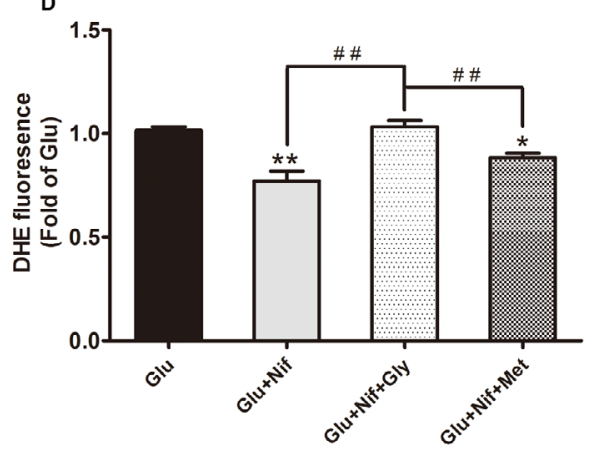

Fig. 3. Nifedipine + glibenclamide combined therapy significantly decreased the NO level and increased the $\mathrm{O}_{2}^{-}$level compared to nifedipine monotherapy in high glucose-treated HUVECs. (A, B) The NO level was significantly decreased by nifedipine + glibenclamide combination therapy compared to nifedipine monotherapy in high glucose-treated HUVEC, while nifedipine + metformin combination therapy significantly increased the NO level in high glucose-treated HUVECs. (C, D) The $\mathrm{O}_{2}^{-}$level was significantly decreased by nifedipine monotherapy in high glucose-treated HUVECs. Compared to the nifedipine monotherapy group, nifedipine + glibenclamide combined therapy significantly increased $\mathrm{O}_{2}^{-}$level in high glucose-treated HUVECs. ${ }^{*} P<0.05,{ }^{* *} P<0.01$ vs. Glu ${ }^{\# *} P<0.01 . \mathrm{n}=6$.

$1.00 \pm 0.017, P<0.01 ;$ Fig. 3). However, compared to nifedipine monotherapy, nifedipine + glibenclamide combined therapy significantly decrease the NO level and increased $\mathrm{O}_{2}^{-}$level in high glucose-treated HUVECs (NO level: $0.775 \pm 0.036$ vs $1.23 \pm 0.037, P<0.01 ; O_{2}{ }^{-}$level: $1.03 \pm 0.031$ vs $0.772 \pm 0.047, P<0.01$; Fig. 3 ). The combination therapy of nifedipine and metformin significantly increased the $\mathrm{NO}$ and $\mathrm{O}_{2}{ }^{-}$levels in high glucose-treated HUVECs (data not shown; Fig. 3). In the case of irbesartan, for both monotherapy and combined therapy with antidiabetic agents, the ARB antihypertensive agent significantly increased the NO level and decreased the $\mathrm{O}_{2}^{-}$level in the high glucose-impaired HUVECs (data not shown; Fig. 4).

Nifedipine + glimepiride combined therapy showed no protective effect from high glucoseinduced migration incapacity in HUVECs; however, monotherapies did

To investigate whether mutual antagonism was present in other new generation sulphonylureas, we examined the migration capacity in HUVECs co-treated with nifedipine and glimepiride, a third-generation sulphonylurea hypoglycaemic agent [21]. It was found that nifedipine combined with glimepiride did not affect the high glucose-impaired migration capacity of the HUVECs $(0.493 \pm 0.033$ vs $0.561 \pm 0.007, P>0.05$; Fig. 5). Meanwhile, glimepiride combined with irbesartan significantly improved the migration incapacity in the high glucose-treated HUVECs (1.15 \pm 0.048 vs $0.561 \pm 0.007, P<0.01$; Fig. 5 ).

\section{Discussion}

The major findings of the present study are as follows: 1) there is an antagonistic interaction between nifedipine and glibenclamide/glimepiride during endothelial cell function; 2) co-administration of nifedipine and metformin, irbesartan and glibenclamide/ 


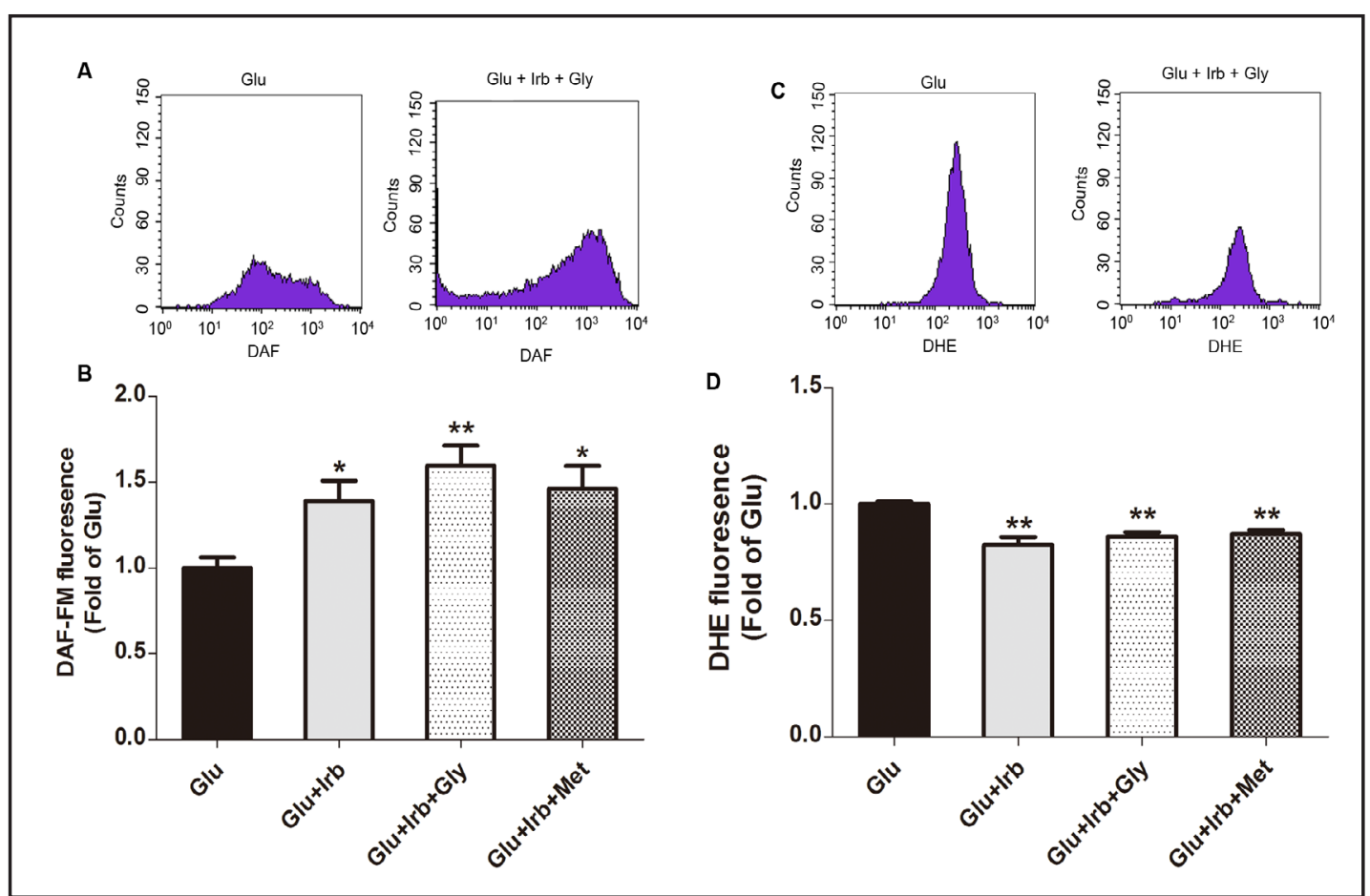

Fig. 4. Both irbesartan monotherapy and combination therapy significantly increased the NO level and decreased the $\mathrm{O}_{2}{ }^{-}$level in high glucose-treated HUVECs. (A, B) The NO level was significantly decreased by irbesartan monotherapy and irbesartan + glibenclamide/metformin combined therapy in high glucose-treated HUVEC. (C, D) The $\mathrm{O}_{2}^{-}$level was significantly decreased by irbesartan monotherapy and irbesartan + glibenclamide/metformin combined therapy in high glucose-treated HUVECs. ${ }^{*} P<0.05,{ }^{* *} P<0.01$ vs. Glu $\mathrm{n}=6$.

glimepiride/metformin reversed the endothelial cell dysfunction induced by high glucose; and 3) the antagonistic interaction between nifedipine and glibenclamide might be partially attributed to their effects on intracellular $\mathrm{NO}$ and $\mathrm{O}_{2}^{-}$levels. These results indicate that, compared to combination therapy of nifedipine and sulphonylureas, co-administration of nifedipine and metformin, irbesartan and glibenclamide/glimepiride/metformin might potentially exert a better effect on endothelial cell protection in the patients suffering from both hypertension and diabetes.

Hypertension and diabetes are two serious interrelated conditions that coexist at a greater frequency than chance alone would predict. Hypertension in diabetic patients markedly increases the risk and accelerates the course of cardiac disease, peripheral vascular disease, stroke, retinopathy and nephropathy. The factors that increase the morbidity of hypertension in diabetic patients must still be elucidated. Diabetic nephropathy greatly contributes to the development of hypertension in diabetic patients, particularly patients with type I diabetes. However, the aetiology of hypertension in the majority of diabetic patients cannot be explained by underlying renal disease. Augmented exchangeable sodium might play a role in the pathogenesis of blood pressure in diabetics [22]. It has been shown that hypertension is also a potent risk factor for diabetic macrovascular and microvascular disease [23], which challenges the optimization of the antihypertensive therapy in diabetic patients.

There is no doubt that cardiovascular complications are at the centre of therapy in hypertensive patients with concomitant diabetes. Hypertension, diabetes and hypertensiondiabetes co-morbidity strongly increases the risk of cardiovascular diseases [24, 25]. It has been demonstrated that the combination of diabetes and hypertension results in a greater impairment of cardiac contractile function than what is observed with either disease alone 
Fig. 5. Nifedipine + glimepiride combination therapy cancelled the monotherapy protection from migration incapacity, which was induced by $33 \mathrm{mM}$ glucose in the HUVECs. (A) Representative images of the migration assay. (B) The results of the migration assay of HUVECs. The values are normalised to the controls. ${ }^{* *} P<0.01, \mathrm{n}$ $=15$. Scale bar: $100 \mu \mathrm{m}$. Con, cells incubated in RAPI 1640 medium; Glu, cells incubated in $33 \mathrm{mM}$ glucose (high glucose) for 24 hours; Glu + Nif, high glucose-treated HUVECs incubated in $1 \mu \mathrm{M}$ nifedipine for 24 hours; Glu + Irb, high glucose-treated HUVECs incubated in $5 \mu \mathrm{M}$ irbesartan for 24 hours; Glu + Glm, high glucose-treated HUVECs incubated by $1 \mu \mathrm{M}$ glimepiride for 24 hours; Glu + Nif + Glm,

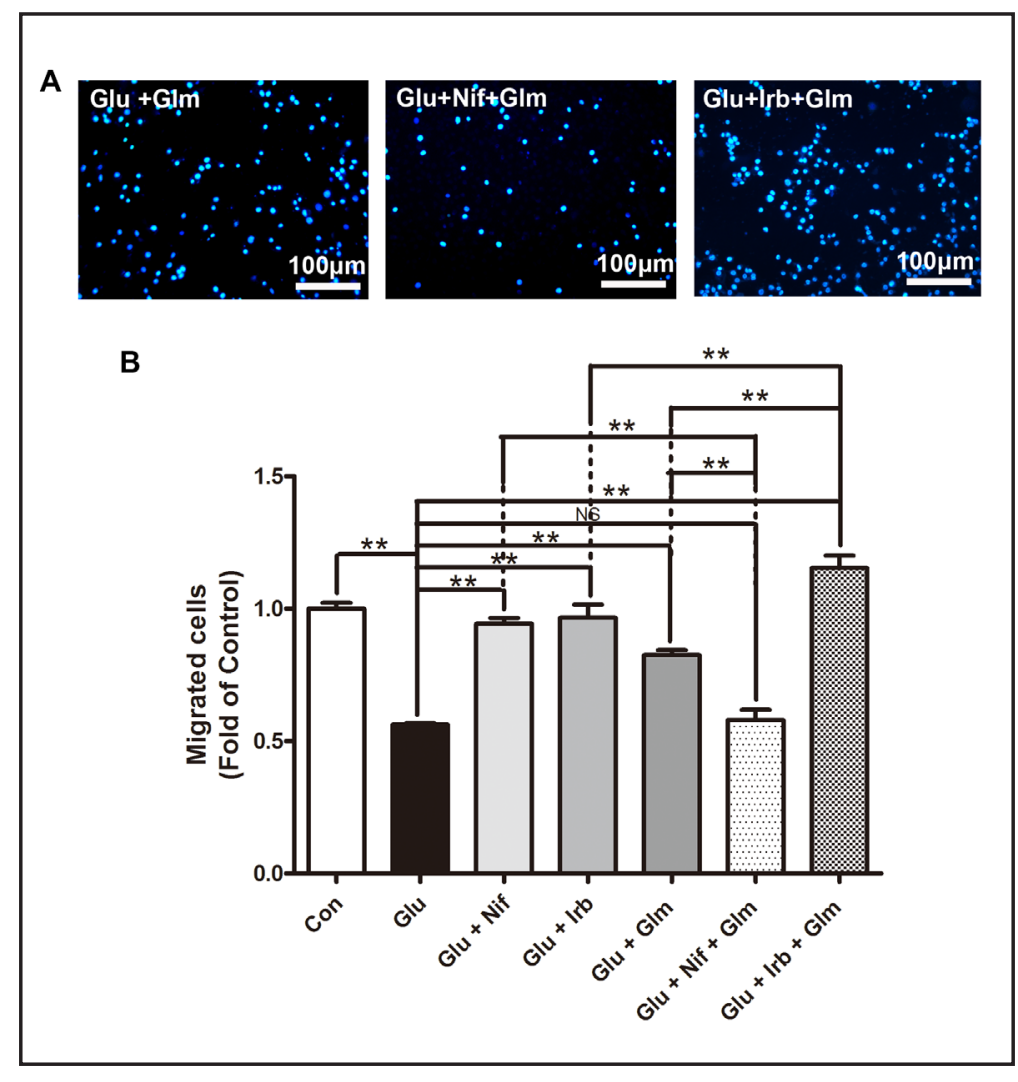
high glucose-treated HUVECs incubated in $1 \mu \mathrm{M}$ nifedipine and $1 \mu \mathrm{M}$ glimepiride for 24 hours; Glu + Irb + Glm, high glucose-treated HUVECs incubated in $5 \mu \mathrm{M}$ irbesartan and $1 \mu \mathrm{M}$ glimepiride for 24 hours.

[26].The underlying pathogenesis lies at the cellular level in the blood vessel wall, which intimately involves the function of endothelial cells. Endothelium emerges as a key target organ of damage in diabetes mellitus, which is enhanced in the presence of hypertension [27]. Endothelial dysfunction is one manifestation of the many changes induced by metabolic abnormalities that accompany diabetes and hypertension. Therefore, the reservation of endothelial function is necessary for the overall treatment of the hypertension-diabetes continuum. This present study indicated that the migration capacity of HUVECs was the key indicator of endothelial cell function.

Calcium channel blockers (CCB) are an indispensable category of anti-hypertensive drugs [28]. Nifedipine is a calcium channel blocker that is widely used in clinics [29]. Decreased blood vessel wall elasticity and ageing could increase the resistance to the vessel wall, thus affecting blood pressure levels. The intracellular calcium concentration increases as the calcium channels open on the vascular walls, thereby elevating vascular resistance and blood pressure [30]. By binding to the calcium channel, CCBs prevent calcium ions from flowing into the vascular cells, thereby relaxing blood vessels and decreasing blood pressure $[31,32]$. However, the glucose-lowering effect of sulphonylurea is attributed to the increase of the intracellular $\mathrm{Ca}^{2+}$ concentration that occurs by closing the ATP-sensitive potassium channel by specifically binding to sulphonylurea receptors on cellular membrane, which could stimulate insulin secretion of pancreatic $\beta$ cell [33-35]. Therefore, the interaction between CCBs and sulphonylureas on HUVECs, as showed in the present work, might be partially attributed to the mutually antagonistic effect on the $\mathrm{Ca}^{2+}$ concentration.

It was found that nifedipine + metformin treatment improved the migration capacity of HUVECs impaired by high glucose. Metformin enhances sodium pump activity and nitric oxide (NO) production, thereby decreasing the intracellular calcium levels $\left(\mathrm{Ca}^{2+}\right)$ and 
vasoconstriction in vascular smooth-muscle cells [36, 37]. Its hypoglycaemic effect occurs by increasing the anaerobic glycolysis of surrounding tissue sugar [37]. However, nifedipine and metformin are both commonly metabolized through hepatic CYP2C and 3A subfamilies. Choi et al. have found that the area under the curve of nifedipine $(3 \mathrm{mg} / \mathrm{kg})$ or metformin $(100 \mathrm{mg} /$ $\mathrm{kg}$ ) was significantly greater than that of each drug alone, which might be primarily due to the competitive inhibition for metabolism after the simultaneous single oral administration of both drugs [38]. Our results also showed that nifedipine + metformin therapy attenuated the high glucose-induced migration incapacity of HUVECs.

ARBs prevent the hypertensive effects of angiotensin II through selective blockade of the angiotensin II type 1 (AT1) receptor [39]. The angiotensin-II-receptor blocker irbesartan is effective in protecting against the nephropathy progression induced by type 2 diabetes, independent of its reduction in blood pressure [40]. A systematic review of 24 studies involving antihypertensive drugs found that the incidence of diabetes is unchanged or decreased by angiotensin receptor blockers [41]. Furthermore, Riccardo et al. have demonstrated that irbesartan but not amlodipine suppresses diabetes-associated atherosclerosis [42]. Our results showed that irbesartan could improve the high glucosedamaged migration capacity of HUVECs with or without anti-diabetic therapy (metformin or glibenclamide). Ishibashi et al. have reported that combination therapy with metformin and irbesartan demonstrates therapeutic potential in diabetic nephropathy [43].

Nitric oxide (NO) derived from endothelial NO synthase (eNOS) is regarded as a protective factor against cardiovascular diseases. It was shown that up-regulation of eNOS expression levels, together with enhanced phosphorylation, could attenuate endothelial dysfunction in coronary artery disease [44]. Leeson et al. have demonstrated that carriage of an endothelial nitric oxide synthase polymorphism was associated with functional changes in the endothelium and in cardiovascular disease [45]. Furthermore, uncoupling the endothelial nitric oxide synthase resulting in superoxide anion $\left(\mathrm{O}_{2}^{-}\right)$formation instead of nitric oxide (NO) causes diabetic endothelial dysfunction $[8,9,46]$. It has been reported that NO preservation protected endothelial dysfunction under high glucose conditions [47]. Previous studies have confirmed that hypertension, diabetes and other risk factors could lead to oxidative stress in endothelial cells $[48,49]$. Other reports have also proposed that HUVECs mobilization was related with NO-mediated signaling pathways [50]. The current study focused on the $\mathrm{NO}$ release and $\mathrm{O}_{2}{ }^{-}$level to investigate the underlying mechanism of endothelial cell function. We found that nifedipine combined with glibenclamide significantly increased $\mathrm{O}_{2}^{-}$levels and decreased NO levels, which might partly contribute to the antagonistic effect of the two agents. Other studies have shown that mitochondrial dysfunction might contribute to diabetic complications [51].

An analysis of prescribing patterns in a general hospital in Taiwan demonstrated that most diabetic hypertensive patients were treated with combination therapy for glucose and blood pressure control, in which sulfonylurea alone or combined with metformin were the most popular medications for glycemic control and calcium-channel blockers were most commonly used for blood pressure control [52]. Accordingly, it is indicated that some of the diabetic hypertensive patients may potentially take both calcium channel blockers and sulfonylureas.

The current study demonstrated, for the first time, that there is an antagonistic interaction between CCBs (such as nifedipine) and sulphonylureas (such as glibenclamide or glimepiride) during endothelial cell function. These results imply that combination therapy between those two agents warrants further attention in patients suffering from both hypertension and diabetes.

\section{Acknowledgments}

This work was supported by the National Key Basic Research Program of China (973 Program; 2014CB542403), the National Natural Science Foundation of China (81370253 


\section{Cellular Physiology Cell Physiol Biochem 2016;38:2337-2347 and Biochemistry Published online: May 23, $2016 \quad$\begin{tabular}{l|l} 
DOI: 10.1159/00044587 2016 The Author(s). Published by S. Karger AG, Basel \\
www.karger.com/cpb
\end{tabular} \\ Wang et al.: Nifedipine, Sulphonylureas and Endothelial Cell Dysfunction}

and 81170115), and the National Science Foundation of China Key Research Project (81130004).

\section{Disclosure Statement}

None.

\section{References}

1 Mancia G, Fagard R, Narkiewicz K, Redon J, Zanchetti A, Bohm M, Christiaens T, Cifkova R, De Backer G, Dominiczak A, Galderisi M, Grobbee DE, Jaarsma T, Kirchhof P, Kjeldsen SE, et al.: 2013 ESH/ESC guidelines for the management of arterial hypertension: the Task Force for the Management of Arterial Hypertension of the European Society of Hypertension (ESH) and of the European Society of Cardiology (ESC). Eur Heart J 2013;34:2159-2219.

2 Shaw JE, Sicree RA, Zimmet PZ: Global estimates of the prevalence of diabetes for 2010 and 2030. Diabetes Res Clin Pr 2010;87:4-14.

3 Sowers JR, Epstein M, Frohlich ED: Diabetes, Hypertension, and Cardiovascular Disease: An Update. Hypertension 2001;37:1053-1059.

4 Cheung BMY: The hypertension-diabetes continuum. J Cardiovasc Pharm 2010;55:333-339.

5 Hurst C, Thinkhamrop B, Tran HT: The Association between Hypertension Comorbidity and Microvascular Complications in Type 2 Diabetes Patients: A Nationwide Cross-Sectional Study in Thailand. Diabetes Metab J 2015;39:395-404.

6 Vasant H, Paola Z, Paola P: Generalised and abdominal obesity and risk of diabetes, hypertension and hypertension-diabetes co-morbidity in England. Public Health Nutr 2008;11:521-527.

7 Creager MA, Luscher TF, Cosentino F, Beckman JA: Diabetes and vascular disease: pathophysiology, clinical consequences, and medical therapy: Part I. Circulation 2003;108:1527-1532.

8 Thum T, Fraccarollo D, Schultheiss M, Froese S, Galuppo P, Widder JD, Tsikas D, Ertl G, Bauersachs J: Endothelial nitric oxide synthase uncoupling impairs endothelial progenitor cell mobilization and function in diabetes. Diabetes 2007;56:666-674.

9 Rask-Madsen C, King GL: Mechanisms of Disease: endothelial dysfunction in insulin resistance and diabetes. Nat Clin Pract Endocrinol Metab 2007;3:46-56.

10 Vallance P, Calver A, Collier J: The vascular endothelium in diabetes and hypertension. J Hypertens 1992;10:S25-29.

11 Eriksson L, Erdogdu O, Nystrom T, Zhang Q, Sjoholm A: Effects of some anti-diabetic and cardioprotective agents on proliferation and apoptosis of human coronary artery endothelial cells. Cardiovasc Diabetol 2012;11:27.

12 Nathanson D, Nystrom T: Hypoglycemic pharmacological treatment of type 2 diabetes: targeting the endothelium. Mol Cell Endocrinol 2009;297:112-126.

13 Xue M, Qian Q, Adaikalakoteswari A, Rabbani N, Babaei-Jadidi R, Thornalley PJ: Activation of NF-E2-related factor-2 reverses biochemical dysfunction of endothelial cells induced by hyperglycemia linked to vascular disease. Diabetes 2008;57:2809-2817.

14 Kukidome D, Nishikawa T, Sonoda K, Imoto K, Fujisawa K, Yano M, Motoshima H, Taguchi T, Matsumura T, Araki: Activation of AMP-activated protein kinase reduces hyperglycemia-induced mitochondrial reactive oxygen species production and promotes mitochondrial biogenesis in human umbilical vein endothelial cells. Diabetes 2006;55:8.

15 Detaille D, Guigas B, Chauvin C, Batandier C, Fontaine E, Wiernsperger N, Leverve X: Metformin prevents high-glucose-induced endothelial cell death through a mitochondrial permeability transition-dependent process. Diabetes 2005;54:9.

16 Schulz M, Schmoldt A: Therapeutic and toxic blood concentrations of more than 800 drugs and other xenobiotics. Pharmazie 2003;58:28. 


\section{Cellular Physiology Cell Physiol Biochem 2016;38:2337-2347 \begin{tabular}{l|l} 
and Biochemistry Published online: May 23, 2016 & $\begin{array}{l}\text { D) } 2016 \text { The Author(s). Published by S. Karger AG, Basel } \\
\text { www.karger.com/cpb }\end{array}$ \\
\hline
\end{tabular} \\ Wang et al.: Nifedipine, Sulphonylureas and Endothelial Cell Dysfunction}

17 Ueba H, Kuroki M, Hashimoto S, Umemoto T, Yasu T, Ishikawa S, Saito M, Kawakami M: Glimepiride induces nitric oxide production in human coronary artery endothelial cells via a PI3-kinase-Akt dependent pathway. Atherosclerosis 2005;183:35-39.

18 Dong XH, Sun X, Jiang GJ, Chen AF, Xie HH: Dietary intake of sugar substitutes aggravates cerebral ischemic injury and impairs endothelial progenitor cells in mice. Stroke 2015;46:1714-1718.

19 Xie HH, Zhou S, Chen DD, Channon KM, Su DF, Chen AF: GTP cyclohydrolase I/BH4 pathway protects EPCs via suppressing oxidative stress and thrombospondin-1 in salt-sensitive hypertension. Hypertension 2010;56:1137-1144.

20 Sharma AK, Srinivasan BP: Triple verses glimepiride plus metformin therapy on cardiovascular risk biomarkers and diabetic cardiomyopathy in insulin resistance type 2 diabetes mellitus rats. Eur J Pharm Sci 2009;38:433-444.

21 Tsunekawa T, Hayashi T, Suzuki Y, Matsui-Hirai H, Kano H, Fukatsu A, Nomura N, Miyazaki A, Iguchi A: Plasma adiponectin plays an important role in improving insulin resistance with glimepiride in elderly type 2 diabetic subjects. Diabetes Care 2003;26:285-289.

22 Epstein M, Sowers JR: Diabetes mellitus and hypertension. Hypertension 1992;19:403-418.

23 Fuller JH: Epidemiology of hypertension associated with diabetes mellitus. Hypertension 1985;7:II3-7.

24 Hirani V, Zaninotto P, Primatesta P: Generalised and abdominal obesity and risk of diabetes, hypertension and hypertension-diabetes co-morbidity in England. Public Health Nutr 2008;11:521-527.

25 Yu Z, Tang L, Chen L, Li J, Wu W, Hu C: Role for HIF-1alpha and Downstream Pathways in Regulating Neuronal Injury after Intracerebral Hemorrhage in Diabetes. Cell Physiol Biochem 2015;37:67-76.

26 Wold LE, Relling DP, Colligan PB, Scott GI, Hintz KK, Ren BH, Epstein PN, Ren J: Characterization of contractile function in diabetic hypertensive cardiomyopathy in adult rat ventricular myocytes. J Mol Cell Cardiol 2001;33:1719-1726.

27 Hsueh WA, Anderson PW: Hypertension, the endothelial cell, and the vascular complications of diabetes mellitus. Hypertension 1992;20:253-263.

28 Ishimitsu T, Fukuda H, Uchida M, Ishibashi K, Sato F, Nukui K, Nagao M: The therapeutic advantage of combination antihypertensive drug therapy using amlodipine and irbesartan in hypertensive patients: Analysis of the post-marketing survey data from PARTNER (Practical combination therapy of Amlodin and angiotensin II Receptor blocker; safety and efficacy in patients with hypertension) study. Clin Exp Hypertens 2015;37:542-550.

29 Shih CY, Lin MH, Fan HC, Chen FC, Chou TC: Mechanisms of antiplatelet activity of nifedipine: role of peroxisome proliferator-activated receptor-beta-gamma-dependent processes. J Hypertens 2014;32:181192.

30 Navedo MF, Santana LF: CaV1.2 sparklets in heart and vascular smooth muscle. J Mol Cell Cardiol 2013;58:67-76.

31 Schramm M, Towart R: Modulation of calcium channel function by drugs. Life Sci 1985;37:18.

32 Blood Pressure Lowering Treatment Trialists' Collaboration: Effects of different blood-pressure-lowering regimens on major cardiovascular events: results of prospectively-designed overviews of randomised trials. Lancet 2003;362:1527-1535.

33 Skillman TG, Feldman JM: The pharmacology of sulfonylureas. Am J Med 1981;70:12.

34 Kantor PF, Coetzee WA, Carmeliet EE, Dennis SC, Opie LH: Reduction of ischemic K+ loss and arrhythmias in rat heart. Circ Res 1990;66:9.

35 Renstrom E, Barg S, Thevenod R, Rorsman P: Sulfonylurea-mediated stimulation of insulin exocytosis via an ATP-sensitive K+ channel-independent action. Diabetes 2002;51:4.

36 Kirpichnikov D, McFarlane SI, Sowers JR: Metformin: An update. Ann Intern Med 2002;137:9.

37 Palomba S, Falbo A, Zullo F, Orio F, Jr.: Evidence-based and potential benefits of metformin in the polycystic ovary syndrome: a comprehensive review. Endocr Rev 2009;30:1-50.

38 Choi YH: Pharmacokinetic and pharmacodynamic interaction between nifedipine and metformin in rats: competitive inhibition for metabolism of nifedipine and metformin by each other via CYP isozymes. Xenobiotica 2012;42:483-495.

39 Rice AS, Dworkin RH, McCarthy TD, Anand P, Bountra C, McCloud PI, Hill J, Cutter G, Kitson G, Desem N, Raff M, group EMAs: EMA401, an orally administered highly selective angiotensin II type 2 receptor antagonist, as a novel treatment for postherpetic neuralgia: a randomised, double-blind, placebo-controlled phase 2 clinical trial. Lancet 2014;383:1637-1647. 


\section{Cellular Physiology Cell Physiol Biochem 2016;38:2337-2347 \begin{tabular}{ll|l} 
DOI: 10.1159/000445587 & $\begin{array}{l}\text { O 2016 The Author(s). Published by S. Karger AG, Basel } \\
\text { www.karger.com/cpb }\end{array}$
\end{tabular} \\ Wang et al.: Nifedipine, Sulphonylureas and Endothelial Cell Dysfunction}

40 Lewis EJ, Hunsicher LG, Clarke WR, Berl T, Pohl MA, Lewis JB, Ritz E, Atkins RC, Rohde R, Raz I: Renoprotective effect of the angiotensin-receptor antagonist Irbesartan in patients with nephropathy due to Type 2 Diabetes. New Engl J Med 2001;345:10.

41 Padwal R, Laupacis A: Antihypertensive therapy and incidence of type 2 diabetes: a systematic review. Diabetes Care 2004;27:247-255.

42 Riccardo C, Allen TJ, Markus L, Zemin C, Vicki T, Cooper ME, Jandeleit-Dahm KA: Irbesartan but not amlodipine suppresses diabetes-associated atherosclerosis. Circulation 2004;109:1536-1542.

43 Ishibashi Y, Matsui T, Takeuchi M, Yamagishi S: Beneficial effects of metformin and irbesartan on advanced glycation end products (AGEs)-RAGE-induced proximal tubular cell injury. Pharmacol Res 2012;65:297302.

44 Hambrecht R, Adams V, Erbs S, Linke A, Krankel N, Shu Y, Baither Y, Gielen S, Thiele H, Gummert JF, Mohr FW, Schuler G: Regular physical activity improves endothelial function in patients with coronary artery disease by increasing phosphorylation of endothelial nitric oxide synthase. Circulation 2003;107:31523158.

45 Leeson CPM, Hingorani AD, Mullen MJ, Jeerooburkhan N, Kattenhorn M, Cole TJ, Muller DPR, Lucas A, Humphries SE, Deanfield JE: Glu298Asp endothelial nitric oxide synthase gene polymorphism interacts with environmental and dietary factors to influence endothelial function. Circ Res 2002;90:1153-1158.

46 Kanikarla-Marie P, Jain SK: Hyperketonemia (acetoacetate) upregulates NADPH oxidase 4 and elevates oxidative stress, ICAM-1, and monocyte adhesivity in endothelial cells. Cell Physiol Biochem 2015;35:364373.

47 Wang F, Pu C, Zhou P, Wang P, Liang D, Wang Q, Hu Y, Li B, Hao X: Cinnamaldehyde prevents endothelial dysfunction induced by high glucose by activating Nrf2. Cell Physiol Biochem 2015;36:315-324.

48 Cai H, Harrison DG: Endothelial dysfunction in cardiovascular diseases: The role of oxidant stress. Circ Res 2000;87:6.

49 Harrison D, Griendling KK, Landmesser U, Hornig B, Drexler H: Role of oxidative stress in atherosclerosis. Am J Cardiol 2003;91:7-11.

50 Konya H, Katsuno T, Tsunoda T, Yano Y, Kamitani M, Miuchi M, Hamaguchi T, Miyagawa J, Namba M: Effects of combination therapy with mitiglinide and voglibose on postprandial plasma glucose in patients with type 2 diabetes mellitus. Diabetes Metab Syndr Obes 2013;6:317-325.

51 Veluthakal R, Kumar B, Mohammad G, Kowluru A, Kowluru RA: Tiam1-Rac1 Axis Promotes Activation of p38 MAP Kinase in the Development of Diabetic Retinopathy: Evidence for a Requisite Role for Protein Palmitoylation. Cell Physiol Biochem 2015;36:208-220.

52 Cheng SF, Hsu HH, Lee HS, Lin CS, Chou YC, Tien JH: Rational pharmacotherapy in the diabetic hypertension: analysis-prescribing patterns in a general hospital in Taiwan. J Clin Pharm Ther 2004;29:547-558. 